\title{
Sex differences in heart rate variability: a longitudinal study in international elite cross-country skiers
}

\author{
Daniela Schäfer ${ }^{1}$ Gard Filip Gjerdalen ${ }^{2}$ Erik Ekker Solberg ${ }^{3}$ Maria Khokhlova ${ }^{4}$. \\ Victoria Badtieva $^{4} \cdot$ David Herzig $^{1} \cdot$ Lukas Daniel Trachsel $^{1} \cdot$ Patrik Noack $^{5}$. \\ Laura Karavirta $^{6} \cdot$ Prisca Eser $^{1} \cdot$ Hugo Saner $^{1} \cdot$ Matthias Wilhelm $^{1}$
}

Received: 17 February 2015 / Accepted: 9 May 2015 / Published online: 23 May 2015

(C) Springer-Verlag Berlin Heidelberg 2015

\begin{abstract}
Purpose Exercise-related sudden cardiac deaths (SCD) occur with a striking male predominance. A higher sympathetic tone in men has been suggested as risk factor for SCD. Elite athletes have the highest risk for exerciserelated SCD. We aimed to analyze the autonomic nervous system of elite cross-country skiers from Norway, Russia and Switzerland in supine position and after orthostatic challenge in various training periods (TP).

Method Measurements of heart rate variability (HRV) were performed on a weekly basis over 1 year using an orthostatic challenge test with controlled breathing. Main outcome parameters were the high-frequency power in supine position (HFsupine) as marker of cardiac parasympathetic activity and the low-frequency/high-frequency power ratio after orthostatic challenge (LF/HFstand) as marker of cardiac sympathetic activation. Training intensity and duration were recorded daily and expressed as training
\end{abstract}

Communicated by Keith Phillip George.

Matthias Wilhelm

matthias.wilhelm@insel.ch

Division of Preventive Cardiology and Sports Medicine, University Clinic for Cardiology, Inselspital University Hospital and University of Bern, 3010 Bern, Switzerland

2 Section of Vascular Investigations, Oslo University Hospital, Bjorknes College, Oslo, Norway

3 Diakonhjemmet Sykehus, Oslo, Norway

4 Moscow Department of Public Health, Moscow Research and Practical Center of Medical Rehabilitation, Restorative and Sports Medicine, Moscow, Russia

5 Swiss Olympic Medical Base, St. Gallen, Switzerland

6 Polar Electro Oy, Kempele, Finland strain. The training year was divided into three TPs. An average of weekly HRV measurements was calculated for each TP.

Result Female $\left(n=19, V \mathrm{O}_{2 \max } 62.0 \pm 4.6 \mathrm{ml} \mathrm{kg}^{-1} \mathrm{~min}^{-1}\right.$, age $25.8 \pm 4.3$ years $)$ and male $\left(n=16, V \mathrm{O}_{2 \max } 74.3 \pm 6.3\right.$ $\mathrm{ml} \mathrm{kg} \mathrm{min}^{-1}$, age $24.4 \pm 4.2$ years) athletes were included. Training strain was comparable between sexes (all $p>0.05$ ) and changed between TPs (all $p<0.05$ ) while no HRV parameters changed over time. There were no sex differences in HFsupine while the LF/HFstand was significantly higher in male athletes in all TPs.

Conclusion For a comparable amount of training, male athletes showed constantly higher markers of sympathetic activity after a provocation maneuver. This may explain part of the male predominance in sports-related SCD.

Keywords Autonomic nervous system $\cdot$ Heart rate variability $\cdot$ Orthostatic test $\cdot$ Athletes $\cdot$ Endurance .

Training

\section{Abbreviations}

ANOVA Analysis of variance

ANS Autonomic nervous system

$\mathrm{CP} \quad$ Competition period

HF High-frequency power

HRV Heart rate variability

LF Low-frequency power

LF/HF Low-frequency/high-frequency power ratio

MeanRR Mean of the R-R intervals

PP1 Preparation period 1

PP2 Preparation period 2

RMSSD The square root of the mean squared differences of successive $\mathrm{R}-\mathrm{R}$ intervals

RPE Rate of perceived exertion

SDNN Standard deviation of all R-R intervals 


$\begin{array}{ll}\text { SCD } & \text { Sudden cardiac death } \\ \text { Sup } & \text { In supine position } \\ \text { Stand } & \text { Standing after orthostatic challenge } \\ \text { TP } & \text { Training periods }\end{array}$

\section{Introduction}

A higher risk for sudden cardiac death (SCD) in young athletes is associated with a higher competition level (Corrado et al. 2006; Harmon et al. 2011). Men have been shown to have an increased risk for SCD (Kannel and Schatzkin 1985) and male sex has also been reported to be an additional risk factor for sports-related SCD, illustrated by the striking male predominance of SCD in young competitive athletes (Maron et al. 2009). Most cases are caused by an underlying cardiac disease, mainly hypertrophic cardiomyopathy, premature coronary artery disease and congenital coronary anomalies (Maron et al. 2009). During exerciseinduced myocardial ischemia, the enhanced sympathetic nerve drive may trigger ventricular fibrillation (Verrier and Kwaku 2004; Zhou et al. 2008). Animal studies suggested that vagal activation may have a protective effect against ventricular arrhythmias induced by acute myocardial ischemia (Billman 2009). Numerous studies examined sex differences in HRV and the majority found a lower LF/HF power ratio (Agelink et al. 2001; Liao et al. 1995; Ramaekers et al. 1998) and lower LF power (Agelink et al. 2001; Liao et al. 1995; Ryan et al. 1994) in women compared to men. These data suggest a higher sympathetic and/or lower vagal activity in males compared to females. However, it should be mentioned that results reporting markers of parasympathetic activity such as absolute HF power showed conflicting results. Some studies have reported significantly higher HF power at rest in women compared to men (Barnett et al. 1999; Fukusaki et al. 2000) while others have reported similar HF power between sexes (Agelink et al. 2001; Fürholz et al. 2013; Ramaekers et al. 1998). Absolute HF power is dependent on HR (Sacha et al. 2014) and the conflicting results may therefore be a consequence of sex differences in HR (Fürholz et al. 2013). Endurance training increases vagal activity, both in female and male athletes (Carter et al. 2003). However, it is currently not known whether the high training loads of elite athletes may increase vagal tone to a saturation level (Buchheit 2014) where sex differences may subside. Additionally to parasympathetic tone at rest, a provocation maneuver is reflective of sympathetic responsiveness for which no saturation effect has been postulated.

The primary aim of the present study was therefore to investigate sex difference in the autonomic nervous system (ANS) activity of elite cross-country skiers over the duration of a whole training year. We hypothesized that male athletes have lower markers of vagal activity in supine position, and higher markers of sympathetic activity after an orthostatic challenge test in all TPs.

Further, it has been shown that the cardiac autonomic nervous activity may vary within different training periods. Very intensive exercise training, such as performed by male world class rowers or recreational marathon runners, resulted in a conversion from cardiac vagal to sympathetic predominance (Hedelin et al. 2000; Iellamo et al. 2002). It is presently unknown whether HRV parameters change between different training periods in elite crosscountry skiers and whether such changes would be different between sexes. Therefore, the second aim of the present study was to investigate sex-specific reactions of HRV on different training periods in elite cross-country skiers.

\section{Methods}

Elite female and male cross-country skiers from either national, junior national or regional teams from Norway, Russia and Switzerland were recruited to participate in the study during the Olympic Season 2013/2014. Inclusion criteria were age 18-35 years and being an active athlete of the International Ski Federation (FIS). Exclusion criteria were compliance with home-based HRV measurements of $<50 \%$ during the study period or injuries and sickness that stopped the athlete from continuation of planned training for more than 4 weeks. The study was approved by all national ethics committees and all participants signed the informed consent.

Training of elite cross-country skiers was monitored for the duration of 1 year on a weekly basis. The athletes performed home-based short-term HRV measurements once per week. Measurements were performed in the morning after awakening on a day that followed a low-intensity training day. Maximal oxygen uptake $\left(V \mathrm{O}_{2 \max }\right)$, body weight and height were taken from their yearly laboratory performance test at their respective national sports institute.

Home-based beat-to-beat $\mathrm{R}$-wave to $\mathrm{R}$-wave intervals ( $\mathrm{R}-\mathrm{R}$ intervals) were recorded in the morning once a week after awakening with a Polar RS800CX computer (Polar Electro Oy, Kempele, Finland). Validity of Polar RS800 to measure $\mathrm{R}-\mathrm{R}$ intervals has been demonstrated (Wallen et al. 2012). A smartphone-derived metronome was used to provide standardized breathing frequency of $0.25 \mathrm{~Hz}$ (15 breaths/min). Short-term recordings were performed in supine position and after an orthostatic challenge. After 5 min recording in supine position, athletes were verbally instructed by the metronome to stand up and stand quietly for another $5 \mathrm{~min}$. Data was uploaded to the Polar Pro Trainer 5 software and transmitted via electronic mail to the core lab (University Hospital Bern) for further analysis. 
$\mathrm{R}-\mathrm{R}$ intervals of the measurements were transferred to Kubios-HRV (V2.1, Department of Physics, University of Kuopio, Finland) (Niskanen et al. 2004) software and analyzed as recommended by the European Society of Cardiology Task Force (Camm 1996). Trend components were removed using the smoothness priors method (Lamda 500, $f_{\mathrm{c}}=0.035 \mathrm{~Hz}$ ). Analysis was performed for $4 \mathrm{~min}$ segments in supine and standing position using fast Fourier transformation. The segment for supine position started 4 min before standing up and the segment for standing started at the shortest $\mathrm{R}-\mathrm{R}$ interval. The following timedomain and frequency-domain parameters were calculated for each supine and standing segment: Time domain: Mean of the R-R intervals [MeanRR (ms)], standard deviation of all $\mathrm{R}-\mathrm{R}$ intervals (SDNN), the square root of the mean squared differences of successive $\mathrm{R}-\mathrm{R}$ intervals (RMSSD), frequency domain: low-frequency power (LF) $\left(\mathrm{ms}^{2}\right)$, high-frequency power $(\mathrm{HF})\left(\mathrm{ms}^{2}\right)$ and LF/HF power ratio. Frequency bands were set on $0.15-0.4 \mathrm{~Hz}$ for $\mathrm{HF}$ and 0.04-0.15 Hz for LF (Camm 1996). HF and LF in normalized units (HFn.u. and LFn.u.) were not reported due to their redundancy with $\mathrm{LF} / \mathrm{HF}$ power ratio (Burr 2007). Primary outcome parameters were the HF power in supine position (HFsupine) as marker of vagal tone (Camm 1996) and the LF/HF power ratio after orthostatic challenge (LF/ HFstand) as marker of sympathetic activity (Furlan et al. 2000). All signals were visually corrected with the automated artifact correction filter from Kubios-HRV (artifact correction was set as low as possible to cut out all artifacts).

Training session load was quantified by multiplying rate of perceived exertion (RPE) (Foster 1998; Foster et al. 2001) calculated using the modified Borg scale intensity score (scale from 1 to 10) (Foster et al. 2001) with the duration of the session. Daily training loads were calculated by summing session training loads of each day. These data were recorded by the athletes in an excel sheet on their own computer. The average weekly training load was calculated according to Foster et al. Training monotony was determined by dividing average weekly training load through the standard deviation of the average weekly training load for each athlete. Weekly strain was calculated by multiplying average weekly training load with training monotony. Average weekly intensity was calculated.

All weekly measured HRV and training data were averaged for each TP. TPs were defined as preparation period 1 (PP1) from calendar week 19 to 31 , preparation period 2 (PP2) from calendar week 32 to 46 and competition period (CP) from calendar week 47 to week 14 of the following year. The data was analyzed with SPSS Statistics, Version 21 (IBM Corp. Armont, NY, USA). Normality of the data was examined using the Kolmogorov-Smirnov test. Data is presented as mean \pm standard deviation or median (interquartile range). Non-parametric data were log transformed. Analysis was performed using repeated measures ANOVA with Bonferroni post hoc correction for time, sex and time-sex interaction. A $p$ value of less than 0.05 was considered statistically significant. Sample size calculation for sex differences was based on the data by Fürholz et al. (2013) with a minimum sample size of 15 per group.

\section{Results}

Thirty-five athletes were included in the final analysis, 16 were male $\left(V \mathrm{O}_{2 \max }: 74.3 \pm 6.3 \mathrm{ml} \mathrm{kg}^{-1} \mathrm{~min}^{-1}\right.$, age: $24.4 \pm 4.2$ years, height: $180 \pm 0.05 \mathrm{~cm}$, body weight: $72.5 \pm 5.3 \mathrm{~kg})$ and 19 female $\left(\mathrm{VO}_{2 \max }\right.$ : $62.0 \pm 4.6 \mathrm{ml} \mathrm{kg}^{-1} \mathrm{~min}^{-1}$, age: $25.8 \pm 4.3$ years, height: $171 \pm 0.07 \mathrm{~cm}$, body weight: $62.5 \pm 6.5 \mathrm{~kg}$ ) athletes. Participants were from Norway $(n=16)$, Russia $(n=6)$ and Switzerland $(n=13)$. Two world champions and seven athletes who qualified for the Sotchi Olympics participated in the present study.

An average of $40.5 \pm 8.4$ (84\% of maximal number of measurements) HRV measurements was recorded per person, whereof $10.0 \pm 4.8(77 \%)$ in PP1, $14.6 \pm 2.2$ $(97 \%)$ in PP2 and $15.9 \pm 6.1(80 \%)$ in CP. Training data was recorded for all trainings by all athletes $(100 \%$ compliance).

Training load, monotony and strain were comparable between female and male athletes (all $p>0.05$ ) and changed over time (Table 1).

Significant sex differences were present for $\mathrm{Ln}(\mathrm{LF} /$ HFstand) (Fig. 1) while no sex differences were found for HFsupine.

MeanRR was the only parameter that changed over time in both, supine position and after orthostatic challenge (Table 2).

Adjustment of heart rate dependent HRV parameters with MeanRR as suggested by Sacha et al. (2014) did not change the results.

\section{Discussion}

The main findings of this study were the absence of sex differences in HFsupine and the persistently higher LF/ HFstand in all TPs for male compared to female athletes. Of all markers of the ANS, the significant differences in training load between the three TPs were only reflected by significant changes in MeanRR. For the first time we have shown that for a comparable amount of training in both sexes, male elite athletes showed constantly higher markers of sympathetic activation in the orthostatic challenge but not in supine position. 
Table 1 Training characteristics

\begin{tabular}{|c|c|c|c|c|c|c|}
\hline & PP1 & PP2 & $\mathrm{CP}$ & $p$ value time $\times$ sex & $p$ value time & $p$ value sex \\
\hline Load & $3498 \pm 1186^{\mathrm{c}}$ & $3294 \pm 1070^{c}$ & $2885 \pm 776^{\mathrm{a}, \mathrm{b}}$ & 0.103 & 0.000 & 0.395 \\
\hline Males & $3846 \pm 1320$ & $3387 \pm 1191$ & $2896 \pm 914$ & & & \\
\hline Females & $3223 \pm 1021$ & $3220 \pm 991$ & $2876 \pm 674$ & & & \\
\hline Monotony & $1.60 \pm 0.41^{\mathrm{c}}$ & $1.67 \pm 0.43^{\mathrm{c}}$ & $1.45 \pm 0.39^{\mathrm{a}, \mathrm{b}}$ & 0.499 & 0.003 & 0.501 \\
\hline Males & $1.53 \pm 0.35$ & $1.60 \pm 0.39$ & $1.45 \pm 0.31$ & & & \\
\hline Females & $1.66 \pm 0.45$ & $1.72 \pm 0.46$ & $1.45 \pm 0.45$ & & & \\
\hline Strain & $5830 \pm 2349^{c}$ & $5848 \pm 2625^{\mathrm{c}}$ & $4607 \pm 1801^{\mathrm{a}, \mathrm{b}}$ & 0.620 & 0.000 & 0.539 \\
\hline Males & $6201 \pm 2771$ & $6165 \pm 3350$ & $4658 \pm 2125$ & & & \\
\hline Females & $5538 \pm 1985$ & $5597 \pm 1936$ & $4567 \pm 1559$ & & & \\
\hline Session intensity & $3.95 \pm 1.09$ & $4.14 \pm 1.14$ & $4.16 \pm 1.03$ & 0.057 & 0.113 & 0.866 \\
\hline Males & $4.05 \pm 1.11$ & $4.11 \pm 1.19$ & $4.00 \pm 1.11$ & & & \\
\hline Females & $3.88 \pm 1.11$ & $4.16 \pm 1.14$ & $4.30 \pm 0.96$ & & & \\
\hline
\end{tabular}

Values are given as mean \pm standard deviation. The training load was calculated by multiplying the rate of perceived exertion on a scale from 1 to 10 with session duration. Training monotony was determined by dividing average weekly training load through the standard deviation of the average weekly training load for each athlete. Weekly strain was calculated by multiplying average weekly training load with training monotony (Foster et al. 2001). Significance level was set at $p<0.05$

$P P 1$ preparation period 1; $P P 2$ preparation period 2; $C P$ competition period

${ }^{\text {a }}$ Value is significantly different from PP1

b Value is significantly different from PP2

c Value is significantly different from $\mathrm{CP}$

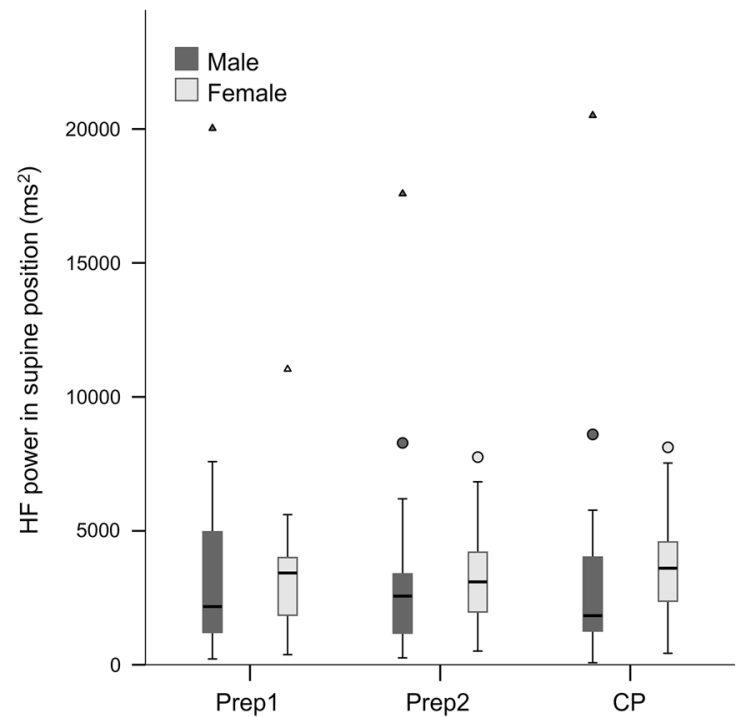

Fig. 1 Sex and time differences in heart rate variability. Sex differences were absent for high-frequency power in supine position (left panel) but LF/HF power ratios after sympathetic provocation maneuver using an orthostatic challenge test were significantly higher in male compared to female athletes during PP1 $(p=0.013)$ and CP

Other studies assessing sex differences at rest reported higher markers of sympathetic tone in male compared to female normal healthy participants (Carter et al. 2003; Ramaekers et al. 1998) recreational athletes (Fürholz

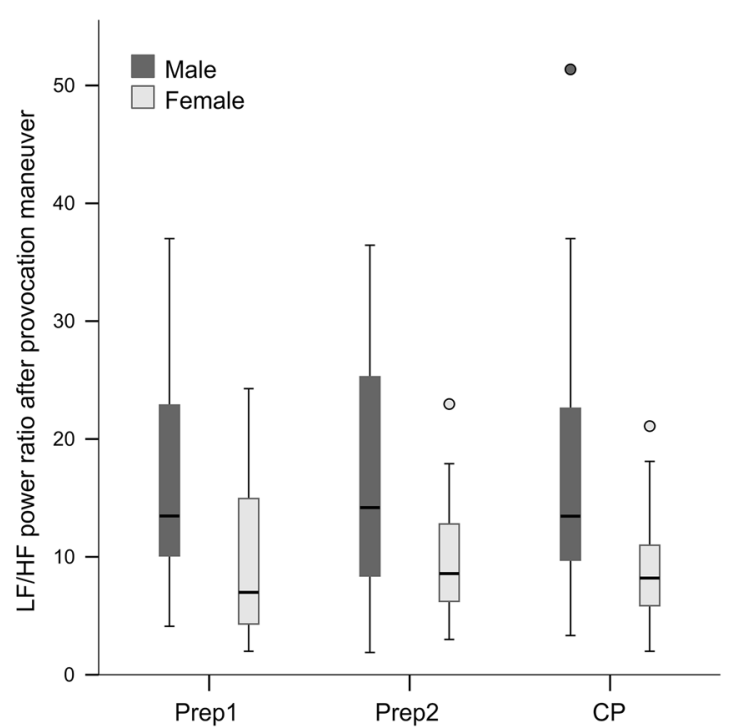

$(p=0.016)$ and by trend in PP2 $(p=0.055)$ (right panel). PP1 preparation period $1 ; P P 2$ preparation period $2 ; C P$ competition period; open circle symbolizes scores greater than the upper quartile plus 1.5 times the interquartile range, open triangle symbolizes scores greater than the upper quartile plus 3 times the interquartile range

et al. 2013) and adolescent cross-country skiers (Hedelin et al. 2000). Contrary to these studies and our hypothesis, we did not find sex differences in HRV at rest. Endurance training is generally accepted to increase HRV markers of 
Table 2 Changes over time, time $\times$ sex interactions and sex differences of heart rate variability parameters in supine position and after an orthostatic challenge

\begin{tabular}{|c|c|c|c|c|c|c|}
\hline & PP1 & PP2 & $\mathrm{CP}$ & $\begin{array}{l}p \text { value } \\
\text { time } \times \text { sex }\end{array}$ & $p$ value time & $p$ value sex \\
\hline \multicolumn{7}{|l|}{ Supine } \\
\hline MeanRR & $1236.7 \pm 171.6$ & $1250.5 \pm 165.1^{\mathrm{c}}$ & $1222.6 \pm 150.4^{\mathrm{b}}$ & 0.461 & 0.033 & 0.311 \\
\hline Males & $1274.7 \pm 151.5$ & $1275.3 \pm 156.4$ & $1250.2 \pm 149.2$ & & & \\
\hline Females & $1204.8 \pm 184.8$ & $1229.6 \pm 173.5$ & $1199.4 \pm 151.5$ & & & \\
\hline SDNN & $72.68 \pm 28.46$ & $75.28 \pm 30.17$ & $74.97 \pm 31.25$ & 0.484 & 0.326 & 0.948 \\
\hline Males & $74.04 \pm 35.70$ & $75.92 \pm 37.20$ & $74.04 \pm 38.29$ & & & \\
\hline Females & $71.53 \pm 21.56$ & $74.74 \pm 23.78$ & $75.74 \pm 24.92$ & & & \\
\hline RMSSD & $98.27 \pm 46.37$ & $101.03 \pm 47.25$ & $99.58 \pm 49.65$ & 0.514 & 0.471 & 0.999 \\
\hline Males & $99.53 \pm 56.82$ & $101.22 \pm 58.82$ & $98.15 \pm 61.60$ & & & \\
\hline Females & $97.20 \pm 36.99$ & $100.86 \pm 36.52$ & $100.79 \pm 38.61$ & & & \\
\hline $\operatorname{lnHF}$ & $7.82 \pm 0.91$ & $7.84 \pm 0.87$ & $7.80 \pm 1.03$ & 0.111 & 0.876 & 0.413 \\
\hline Males & $7.74 \pm 1.07$ & $7.74 \pm 0.99$ & $7.61 \pm 1.23$ & & & \\
\hline Females & $7.89 \pm 0.77$ & $7.93 \pm 0.76$ & $7.99 \pm 0.80$ & & & \\
\hline $\operatorname{lnLF}$ & $7.37 \pm 0.70$ & $7.49 \pm 0.80$ & $7.47 \pm 0.87$ & 0.230 & 0.278 & 0.728 \\
\hline Males & $7.42 \pm 0.86$ & $7.56 \pm 0.91$ & $7.45 \pm 1.01$ & & & \\
\hline Females & $7.32 \pm 0.54$ & $7.40 \pm 0.69$ & $7.50 \pm 0.73$ & & & \\
\hline $\operatorname{lnLF} / \mathrm{HF}$ & $-0.27 \pm 0.716$ & $-0.20 \pm 0.63$ & $-0.13 \pm 0.75$ & 0.468 & 0.144 & 0.316 \\
\hline Males & $-0.20 \pm 0.713$ & $-0.03 \pm 0.55$ & $-0.01 \pm 0.71$ & & & \\
\hline Females & $-0.35 \pm 0.732$ & $-0.36 \pm 0.67$ & $-0.24 \pm 0.80$ & & & \\
\hline \multicolumn{7}{|l|}{ Standing } \\
\hline MeanRR & $848.1 \pm 139.2$ & $838.9 \pm 135.0$ & $817.9 \pm 119.3$ & 0.856 & 0.028 & 0.461 \\
\hline Males & $829.0 \pm 75.9$ & $819.3 \pm 107.1$ & $804.4 \pm 84.7$ & & & \\
\hline Females & $864.2 \pm 176.7$ & $855.4 \pm 155.7$ & $829.4 \pm 143.6$ & & & \\
\hline SDNN & $54.35 \pm 16.33$ & $55.41 \pm 17.06$ & $54.28 \pm 16.29$ & 0.785 & 0.760 & 0.409 \\
\hline Males & $56.35 \pm 17.95$ & $57.52 \pm 18.91$ & $57.41 \pm 18.34$ & & & \\
\hline Females & $52.66 \pm 15.12$ & $53.64 \pm 15.63$ & $51.63 \pm 14.31$ & & & \\
\hline RMSSD & $36.69 \pm 15.14$ & $37.19 \pm 17.39$ & $35.61 \pm 14.39$ & 0.412 & 0.592 & 0.726 \\
\hline Males & $34.51 \pm 15.32$ & $37.36 \pm 22.84$ & $34.71 \pm 17.77$ & & & \\
\hline Females & $38.52 \pm 15.16$ & $37.05 \pm 11.67$ & $36.36 \pm 11.25$ & & & \\
\hline $\operatorname{lnHF}$ & $5.68 \pm 1.03$ & $5.76 \pm 1.06$ & $5.71 \pm 0.90$ & 0.111 & 0.876 & 0.413 \\
\hline Males & $5.47 \pm 0.94$ & $5.64 \pm 1.23$ & $5.61 \pm 1.03$ & & & \\
\hline Females & $5.88 \pm 1.10$ & $5.88 \pm 0.89$ & $5.81 \pm 0.77$ & & & \\
\hline $\operatorname{lnLF}$ & $7.66 \pm 0.67$ & $7.75 \pm 0.67$ & $7.69 \pm 0.74$ & 0.508 & 0.573 & 0.060 \\
\hline Males & $7.85 \pm 0.67$ & $7.89 \pm 0.57$ & $7.93 \pm 0.60$ & & & \\
\hline Females & $7.48 \pm 0.63$ & $7.63 \pm 0.74$ & $7.45 \pm 0.81^{*}$ & & & \\
\hline $\operatorname{lnLF} / \mathrm{HF}$ & $2.31 \pm 0.71$ & $2.36 \pm 0.70$ & $2.33 \pm 0.71$ & 0.619 & 0.794 & 0.015 \\
\hline Males & $2.63 \pm 0.61$ & $2.61 \pm 0.80$ & $2.64 \pm 0.71$ & & & \\
\hline Females & $2.11 \pm 0.71^{*}$ & $2.15 \pm 0.58$ & $2.08 \pm 0.63 *$ & & & \\
\hline
\end{tabular}

Values are given as mean \pm standard deviation. Significance level was set at $p<0.05$

$P P 1$ preparation period 1; $P P 2$ preparation period 2; $C P$ competition period; MeanRR mean of the RR intervals; SDNN standard deviation of all RR intervals; $R M S S D$ square root of the mean of the sum of the squares of differences between adjacent RR intervals; $\ln L F$ natural logarithm from low-frequency power; $l n H F$ natural logarithm from high-frequency power

* Values are significantly different from males $(p<0.05)$

a Value is significantly different from PP1

${ }^{\mathrm{b}}$ Value is significantly different from PP2 $(p<0.05)$

${ }^{c}$ Value is significantly different from $\mathrm{CP}(p<0.05)$ 
parasympathetic activity (Camm 1996; Carter et al. 2003). The training history with a large cumulative training load in the present elite athletes may explain the high values of markers of parasympathetic activity in the present study compared to other studies. It can be speculated that our athletes reached their maximal potential to increase HRV markers of vagal activity. Such a potential saturation of vagal receptors (Kiviniemi et al. 2004) may also explain the absence of differences in HRV markers in the various training periods despite significant changes in training load and strain. Such a hypothesis has also been put forward for other physiological parameters such as $V \mathrm{O}_{2 \max }$, which cannot be improved substantially with increased training intensity or volume in elite endurance athletes once a certain training level has been reached (Losnegard et al. 2013; Lucia et al. 2000).

Orthostatic challenge inhibits cardiac parasympathetic activity and augments sympathetic outflow, both resulting in gradual rise in heart rate (Hilz and Dutsch 2006). It is currently highly debated whether any HRV parameter reflects cardiac sympathetic activity. It is generally accepted that LF fluctuations of HRV at rest are not related to muscle sympathetic nerve activity (Carter et al. 2003). However, when measured in an orthostatic challenge, it has been shown that LF/HF power ratio and muscle sympathetic nerve activation change in parallel (Furlan et al. 2000; Montano et al. 1994), suggesting that this HRV ratio may reflect enhanced adrenergic activity as response to provoked stress. Sex differences in the response to orthostatic challenge have previously been reported for LFn.u. in adolescent cross-country skiers using the tilt test (Hedelin et al. 2000) but have not been studied in adult elite athletes. Since LFn.u. corresponds to LF/HF (Burr 2007), this result is in agreement with our finding. The higher LF/HFstand in male athletes may be an expression of a higher sympathetic reaction compared to female athletes.

The absence of changes in HRV parameters between periods with different training loads is in contrast to the only previous study comparing HRV measurements in cross-country skiers during different TPs (Hedelin et al. 2000). Hedelin et al. (2000) showed increased total variability at rest and reduced LF power in the tilted position in adolescent cross-country skiers before compared to after the competition period. We suggest that this difference may be due to the shorter training history in the adolescent athletes of the Hedelin et al. study where athletes were likely to increase HRV from year to year while this was absent in our athletes because they most probably had reached a saturation level. Controversial results with regard to HRV changes between different TPs were also found in other studies (Iellamo et al. 2002; Manzi et al. 2009; Mazon et al. 2013; Oliveira et al. 2013). We suggest that besides different study populations further reasons for the different findings may have been different training volume and intensity distribution, the different training periodization, the different training history and performance level, the sport mode itself or different measurement methods and study designs to assess HRV.

Individual variances in HRV parameters are quite large while MeanRR has been shown to have the smallest individual variance (Pinna et al. 2007). This may explain why in our study significant changes between TPs were only observed in MeanRR and not in the other HRV parameters. However, the clinical relevance is questionable due to the small change ( 1 heart beat/min for supine and 2 heart beats/ min for standing position when comparing the training period with the shortest and longest MeanRR).

Strengths of our study were the unique longitudinal design, the large sample size in terms of number of elite athletes, number of measurements per athlete, and the international high level of athletes. Further strengths were the averaging of several HRV measurements within one TPs, which reduced the effect of individual confounders on HRV, such as the menstrual cycle in female athletes. Limitations were the usage of HRV measurements as an indirect method to assess the autonomic innervation of the heart and the measurement of sympathetic provocation in the orthostatic test instead of during exercise. HRV measurements in postural changes are thought to be more reliable than during exercise (Buchheit 2014) and were more appropriate for the design of this longitudinal study.

Our results are of special interest in the context of SCD in young athletes, which occur with a striking male predominance and mainly in situations where sympathetic activity is elevated (Kim et al. 2012). Elite athletes have been shown to have the highest risk for sports-related SCD (Harmon et al. 2011). Sex differences after orthostatic challenge but not in supine position in the present study may therefore support the general view that the risk prediction power of ANS tests increases when quantifying autonomic responses to specific provocations rather than studying unprovoked baseline ANS function (Wellens et al. 2014). Up until now, the prognostic significance of the $\mathrm{LF} / \mathrm{HF}$ power ratio after orthostatic challenge is unknown. Further, the physiological background of LF power is not completely clear. At present, the theory of reflection of "baroreflex resonance" in the LF power prevails. Women were shown to have a lesser baroreflex sensitivity (Yang et al. 2012), possibly contributing to their lower LF/HF power ratio. However, when measured in an orthostatic challenge, it has been shown that the LF/ $\mathrm{HF}$ power ratio and muscle sympathetic nerve activation change in parallel (Furlan et al. 2000). Importantly, it can only be hypothesized that a lower LF/HF power ratio in female athletes after orthostatic challenge may be cardio protective. Their lower incidence of SCD may also be 
related to sex differences in cholesterol profile, blood pressure, incidences of underlying cardio-vascular diseases, or different exercise intensities during competitions. However, the assumption that a lower sympathetic activity protects from life-threatening ventricular arrhythmias is plausible and supported by other authors (Iellamo et al. 2002; Ramaekers et al. 1998).

\section{Conclusion}

For a comparable amount of training, male athletes showed constantly higher markers of sympathetic activation after an orthostatic challenge. These results contribute further evidence to the role of the sympathetic predominance as higher risk for SCD in male compared to female athletes (Maron et al. 2009; Verrier and Kwaku 2004; Zhou et al. 2008). Further, the fact that no differences were found in HRV parameters between different training periods despite different training strains indicates that the usage of HRV for training monitoring and steering may be independent of $\mathrm{TP}$ in our population of highly trained endurance athletes.

Acknowledgments We thank all study participants, their coaches and physicians for their contribution and Polar Electro Oy for providing us equipment and technical support.

\section{Conflict of interest None.}

\section{References}

Agelink MW, Malessa R, Baumann B, Majewski T, Akila F, Zeit T, Ziegler D (2001) Standardized tests of heart rate variability: normal ranges obtained from 309 healthy humans, and effects of age, gender, and heart rate. Clin Auton Res 11:99-108

Barnett SR, Morin RJ, Kiely DK, Gagnon M, Azhar G, Knight EL, Lipsitz LA et al (1999) Effects of age and gender on autonomic control of blood pressure dynamics. Hypertension 33:1195-1200

Billman GE (2009) Cardiac autonomic neural remodeling and susceptibility to sudden cardiac death: effect of endurance exercise training. Am J Physiol Heart Circ Physiol 297:H1171-H1193

Buchheit M (2014) Monitoring training status with HR measures: do all roads lead to Rome? Front Physiol 5:73

Burr RL (2007) Interpretation of normalized spectral heart rate variability indices in sleep research: a critical review. Sleep 30:913-919

Camm J (1996) Heart rate variability: standards of measurement, physiological interpretation and clinical use. Task force of the European Society of Cardiology and the North American Society of Pacing and Electrophysiology. Circulation 93:1043-1065

Carter JB, Banister EW, Blaber AP (2003) The effect of age and gender on heart rate variability after endurance training. Med Sci Sports Exerc 35:1333-1340

Corrado D, Basso C, Schiavon M, Thiene G (2006) Does sports activity enhance the risk of sudden cardiac death? J Cardiovasc Med (Hagerstown) 7:228-233

Foster C (1998) Monitoring training in athletes with reference to overtraining syndrome. Med Sci Sports Exerc 30:1164-1168
Foster C, Florhaug JA, Franklin J, Gottschall L, Hrovatin LA, Parker $\mathrm{S}$, Dodge $\mathrm{C}$ et al (2001) A new approach to monitoring exercise training. J Strength Cond Res 15:109-115

Fukusaki C, Kawakubo K, Yamamoto Y (2000) Assessment of the primary effect of aging on heart rate variability in humans. Clin Auton Res 10:123-130

Fürholz M, Radtke T, Roten L, Tanner H, Wilhelm I, Schmid JP, Wilhelm M et al (2013) Training-related modulations of the autonomic nervous system in endurance athletes: is female gender cardioprotective? Eur J Appl Physiol 113:631-640

Furlan R, Porta A, Costa F, Tank J, Baker L, Schiavi R, MosquedaGarcia R et al (2000) Oscillatory patterns in sympathetic neural discharge and cardiovascular variables during orthostatic stimulus. Circulation 101:886-892

Harmon KG, Asif IM, Klossner D, Drezner JA (2011) Incidence of sudden cardiac death in National Collegiate Athletic Association athletes. Circulation 123:1594-1600

Hedelin R, Wiklund U, Bjerle P, Henriksson-Larsen K (2000) Pre-and post-season heart rate variability in adolescent cross-country skiers. Scand J Med Sci Sports 10:298-303

Hilz MJ, Dutsch M (2006) Quantitative studies of autonomic function. Muscle Nerve 33:6-20

Iellamo F, Legramante JM, Pigozzi F, Spataro A, Norbiato G, Lucini D, Pagani M (2002) Conversion from vagal to sympathetic predominance with strenuous training in high-performance world class athletes. Circulation 105:2719-2724

Kannel WB, Schatzkin A (1985) Sudden death: lessons from subsets in population studies. J Am Coll Cardiol 5:141B-149B

Kim JH, Malhotra R, Chiampas G, d'Hemecourt P, Troyanos C, J Cianca, Baggish AL (2012) Cardiac arrest during long-distance running races. N Engl J Med 366:130-140

Kiviniemi AM, Hautala AJ, Seppanen T, Makikallio TH, Huikuri HV, Tulppo MP (2004) Saturation of high-frequency oscillations of $\mathrm{R}-\mathrm{R}$ intervals in healthy subjects and patients after acute myocardial infarction during ambulatory conditions. Am J Physiol Heart Circ Physiol 287:H1921-H1927

Liao D, Barnes RW, Chambless LE, Simpson RJ Jr, Sorlie P, Heiss G (1995) Age, race, and sex differences in autonomic cardiac function measured by spectral analysis of heart rate variability-the ARIC study. Atherosclerosis Risk in Communities. Am J Cardiol 76:906-912

Losnegard T, Myklebust H, Spencer M, Hallen J (2013) Seasonal variations in $V_{\mathrm{O}_{2 \max }}, \mathrm{O}_{2}$-cost, $\mathrm{O}_{2}$-deficit, and performance in elite cross-country skiers. J Strength Cond Res 27:1780-1790

Lucia A, Hoyos J, Perez M, Chicharro JL (2000) Heart rate and performance parameters in elite cyclists: a longitudinal study. Med Sci Sports Exerc 32:1777-1782

Manzi V, Castagna C, Padua E, Lombardo M, D’Ottavio S, M Massaro, Iellamo F (2009) Dose-response relationship of autonomic nervous system responses to individualized training impulse in marathon runners. Am J Physiol Heart Circ Physiol 296:H1733-H1740

Maron BJ, Doerer JJ, Haas TS, Tierney DM, Mueller FO (2009) Sudden deaths in young competitive athletes: analysis of 1866 deaths in the United States, 1980-2006. Circulation 119:1085-1092

Mazon J, Gastaldi A, Di Sacco T, Cozza I, Dutra S, Souza H (2013) Effects of training periodization on cardiac autonomic modulation and endogenous stress markers in volleyball players. Scand J Med Sci Sports 23:114-120

Montano N, Ruscone TG, Porta A, Lombardi F, Pagani M, Malliani A (1994) Power spectrum analysis of heart rate variability to assess the changes in sympathovagal balance during graded orthostatic tilt. Circulation 90:1826-1831

Niskanen JP, Tarvainen MP, Ranta-Aho PO, Karjalainen PA (2004) Software for advanced HRV analysis. Comput Methods Progr Biomed 76:73-81 
Oliveira RS, Leicht AS, Bishop D, Barbero-Alvarez JC, Nakamura FY (2013) Seasonal changes in physical performance and heart rate variability in high level futsal players. Int J Sports Med 34:424-430

Pinna GD, Maestri R, Torunski A, Danilowicz-Szymanowicz L, Szwoch M, La Rovere MT, Raczak G (2007) Heart rate variability measures: a fresh look at reliability. Clin Sci (Lond) 113:131-140

Ramaekers D, Ector H, Aubert AE, Rubens A, Van de Werf F (1998) Heart rate variability and heart rate in healthy volunteers. Is the female autonomic nervous system cardioprotective? Eur Heart J 19:1334-1341

Ryan SM, Goldberger AL, Pincus SM, Mietus J, Lipsitz LA (1994) Gender-and age-related differences in heart rate dynamics: are women more complex than men? J Am Coll Cardiol 24:1700-1707

Sacha J, Barabach S, Statkiewicz-Barabach G, Sacha K, Muller A, Piskorski J, Schmidt G, et al. (2014) Gender differences in the interaction between heart rate and its variability-How to use it to improve the prognostic power of heart rate variability. Int $\mathbf{J}$ Cardiol 171(2):e42-e45

Verrier RL, Kwaku KF (2004) Frayed nerves in myocardial infarction: the importance of rewiring. Circ Res 95:5-6

Wallen MB, Hasson D, Theorell T, Canlon B, Osika W (2012) Possibilities and limitations of the Polar RS800 in measuring heart rate variability at rest. Eur J Appl Physiol 112:1153-1165

Wellens HJ, Schwartz PJ, Lindemans FW, Buxton AE, Goldberger JJ, Hohnloser SH, Wilde AA et al (2014) Risk stratification for sudden cardiac death: current status and challenges for the futuredagger. Eur Heart J 35:1642-1651

Yang H, Cooke WH, Reed KS, Carter JR (2012) Sex differences in hemodynamic and sympathetic neural firing patterns during orthostatic challenge in humans. J Appl Physiol 112:1744-1751

Zhou S, Jung BC, Tan AY, Trang VQ, Gholmieh G, Han SW, Chen LS et al (2008) Spontaneous stellate ganglion nerve activity and ventricular arrhythmia in a canine model of sudden death. Heart Rhythm 5:131-139 